\title{
Optimization of hot air welding process parameters for manufacturing textile transmission lines for e-textiles applications: Part I: Electro-conductive properties
}

Textile Research Journal 2017, Vol. 87(2) 232-243 (C) The Author(s) 2016 Reprints and permissions: sagepub.co.uk/journalsPermissions.nav DOI: $10.1177 / 0040517516629 \mid 40$ trj.sagepub.com

@SAGE

\author{
Senem Kursun Bahadir and Simona Jevšnik
}

\begin{abstract}
This paper presents optimization of the hot air welding process parameters for the formation of textile transmission lines and the electro-conductive properties of these manufactured transmission lines. A dedicated manufacturing set-up has been developed to allow a reliable and flexible textile signal transmission line at adequate conductivity. In order to manufacture textile transmission lines, different welding parameters with different conductive yarns and welding tapes were considered. Layered fabric structures consisting of textile transmission lines and fabrication tolerances were determined, as well as electro-conductive properties for welded samples. It was found that the choice of welding parameters, depending on the materials used for the formation of textile transmission lines, is extremely important for obtaining good electro-conductive properties. In addition, welding tapes and thermoplastic materials play an important role during the set-up of welding process parameters. Results statistically confirmed that welding tapes with conductive yarns can significantly cause a variety of changes in the signal qualities of welded textile transmission lines. The obtained results based on conductivity and signal-to-noise ratios are really promising for the manufacturing of e-textile transmission lines via hot air welding technology.
\end{abstract}

\section{Keywords}

transmission lines, conductive yarn, welding process, electrical resistance, signal transmission, e-textiles

Fabrics used for e-textile applications are required to be flexible and elastic in order to achieve a high comfort of wearing while they are designed for clothing or they are desired to have a low resistance to bending and shearing in order to preserve textile aspects while functioning. Depending on the aim of the application, these demands are inconsistent with the materials and construction profiles. However, the main expected criteria of each electronic fabric is to have a form of conductors connecting individual electronic components together that is flexible while satisfying continuous electrical conductivity with reliable signal transmission. ${ }^{1-3}$ In addition, since such interconnections are a path towards supplying power or transmitting digital/ analog signals to electronic components, satisfying reliable electrical transmission among electronic components without any interruption is a crucial issue within an e-textile system. . $^{3,4}$

To date different textile technologies have been developed and combined for manufacturing conductive threads over textiles for data transmission, such as direct insertion of conductive yarns during weaving or knitting processes; deposition of electro-conductive

Textile Technologies and Design Faculty, Istanbul Technical University, Turkey

\section{Corresponding author:}

Senem Kursun Bahadir, Textile Technologies and Design Faculty, Istanbul Technical University, Istanbul 34437, Turkey.

Email: kursuns@itu.edu.tr 
thin layers on a flat textile surface; overprinting or coating of conductive materials/polymers such as polypyrrole, polyaniline, etc., as well as metal particles, carbon nanotubes and carbon black particles on a flat textile surface; and direct insertion of conductive yarns through sewing or embroidery methods. ${ }^{5-9}$

During the construction stages of textile transmission lines, textiles are subjected to numerous mechanical stresses, which can lead to failure of the line in terms of resistivity and signal transmission. The value of this failure can either decrease the quality of signal transmission or further result in failure of the whole e-textile system. In this context, to apply an insulating layer on these conductive threads can be a possible solution for protecting the transmission line from the several forces acting on them. In addition, these insulated signal transmission lines are able to withstand typical textile handling, such as washing, or when they are subjected to water or wrinkling damage, resistance to abrasion, etc., these insulated layers may even result in preventing probable short circuits during electrical transmission. ${ }^{10,11}$

For industrial applications, methods such as coating, screen printing, ink-jet printing and various thin-film deposition techniques are suggested in the literature for producing conductive threads with such insulated layers. ${ }^{12-14}$ However, no attention has been paid to using welding and bonding techniques for the manufacture of textile signal lines.

The most used welding and bonding technologies for textiles are hot air fabric and hot wedge fabric welding, ultrasonic, laser and radio frequency welding. ${ }^{15-19}$ In the textile arena, two techniques are used to obtain welded seams. In the first technique, a thermoplastic film is used to bond two fabrics together while, in the second one, two thermoplastic fabrics are brought together to stick on each other with the principle based on molecular interlocking of the two surfaces that are in contact with each other at their melt temperature. ${ }^{18,20}$ When the surfaces are subjected to heat, the stabilities of the polymer molecules within the material are disturbed and, hence, disentanglement of the polymer molecules occurs. This phenomenon, leading the molecules to free the chain ends, prepares a condition for strong adhesion of two materials that are in close contact with each other when they are around their melt temperatures. ${ }^{15}$

The literature review concerning weld line formation on textiles mainly focuses on the qualities of the welded seams and it has been reported that the quality of welded seams depends on proper selection of welding parameters (e.g. welding process parameters using hot air: pressure, temperature, velocity) as well as compatibilities of materials with welding techniques. ${ }^{21-26}$
Research is currently being conducted on the formation of a new type of textile transmission line with an insulation layer using hot air welding technologies. In order to manufacture textile transmission lines, different welding parameters with different conductive yarns and welding tapes are considered in order to obtain flexible textile signal transmission lines that are reliable and durable in functionality while preserving the textiles' aspects. The qualities of the welded seams with conductive yarns from various aspects has been discussed using a statistical analysis based on analysis of variance (ANOVA) and the electro-conductive properties of textile transmission lines are assessed based on their electric resistance and signal transference capabilities.

\section{Experimental details}

The development of textile transmission lines for e-textile applications includes a design process based on hot air welding technologies. Planning the circuit of the electrical transmission lines is very complex and depends on many parameters. The quality evaluation parameters of conductive transmission lines vary depending on the purposes within the application arena of e-textiles. Basically, the more important properties of the e-textile transmission lines are their electrical properties in terms of conductivity and signal transference quality. If these properties are at the expected levels, then the textile and mechanical properties play important roles in quality evaluation. Thus, in this study those welded textile transmission lines manufactured via the hot air seam sealing method were tested from several aspects for optimization of the process parameters. A systematic approach for optimization of the welding parameters and materials for manufacturing e-textile transmission lines is given in Figure 1.

Results are presented in this paper of evaluating the electrical properties of manufactured e-textile transmission lines in terms of conductivity and signal quality with the bonding strength, whereas the influence of welding parameters on bending and formability properties, thickness and visual appearances are discussed in Part II with statistical analyses.

\section{Design and manufacturing of textile transmission lines}

The research was carried out on a woven plain fabric with a composition ratio of $60 \%$ polyethylene terephthalate (PET) and 40\% cotton by considering manufacturing issues and compatibilities using the PFAFF 8330 hot air welding machine. The fabric's density in the warp direction was 38 picks $/ \mathrm{cm}$ and in the weft 


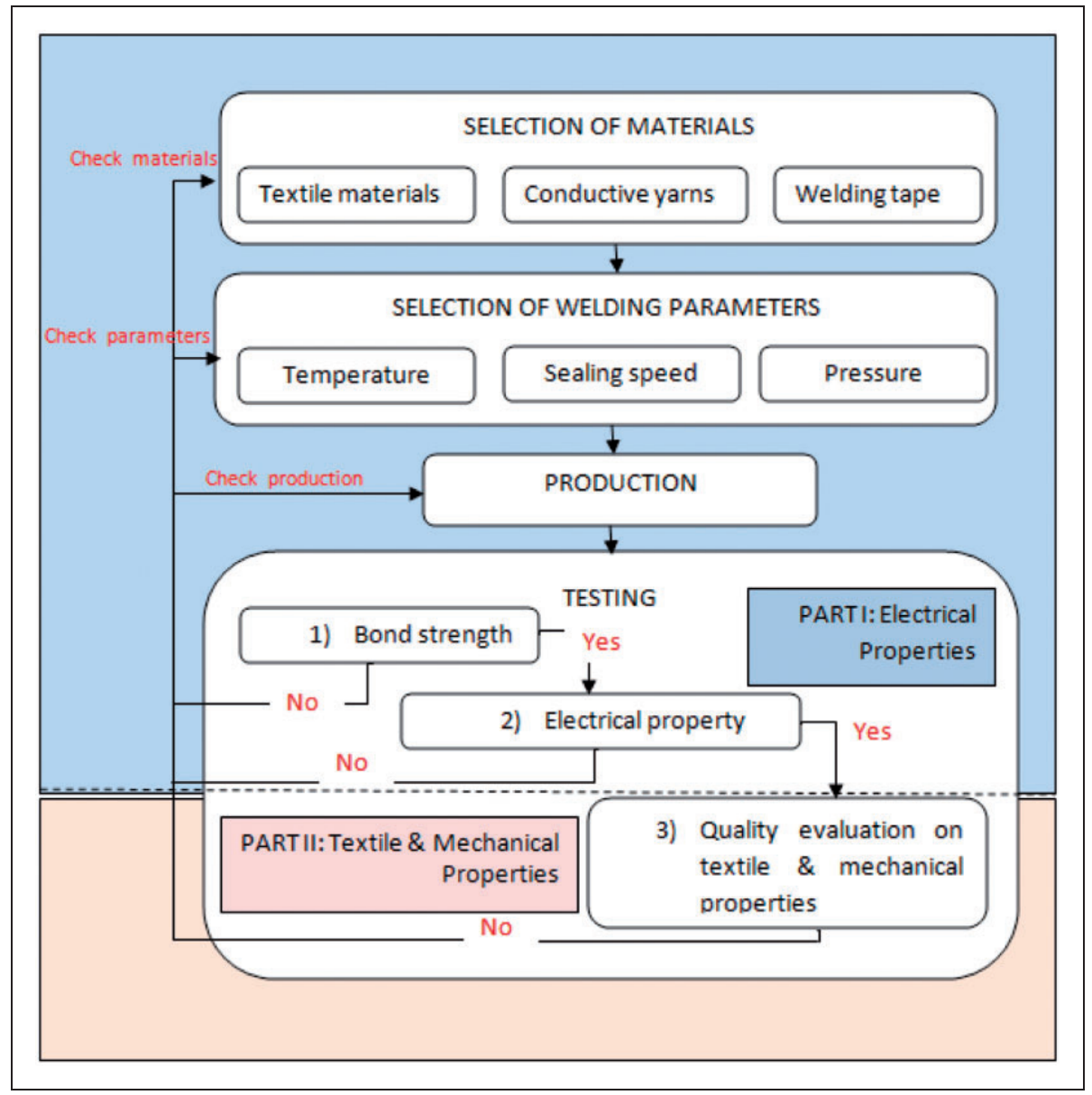

Figure I. Systematic approach for the welding parameters and materials when manufacturing the e-textile transmission lines.

direction was 26 ends $/ \mathrm{cm}$, the thickness was $0.372 \mathrm{~mm}$ and the fabric weight was $225.5 \mathrm{~g} / \mathrm{m}^{2}$.

The welding tape WT1 is made from three layers (layer 1-warp knitted fabric, layer 2-waterproof film and layer 3-hot melt adhesive), with a thickness of $0.355 \mathrm{~mm}$ and width of $20 \mathrm{~mm}$, while tape WT2 is made from two layers (layer 1-waterproof film and layer 2-hot melt adhesive film), thickness being $0.163 \mathrm{~mm}$ and width $20 \mathrm{~mm}$. Both tapes are breathable, waterproof and windproof. The tapes were chosen in order to prevent probable short circuits during signal transmission, as well as for obtaining a water-resistant fabric structure when considering the usage issues of e-textiles.

Commercial conductive yarns were used to create a transmission line in a two-layered fabric structure. The properties of the conductive yarns used for manufacturing the transmission lines are presented in Table 1.

Textile transmission lines are designed in twolayered fabric constructions, as shown in Figure 2. The length of the structure is arranged at $30 \mathrm{~cm}$ while the width is arranged at $5 \mathrm{~cm}$. The conductive yarns were positioned along a straight trajectory in the middle of the fabric without any undulation. Hence, the transmission line shown in Figure 2 was hidden by the replacement of the conductive yarn between the fabric and welding tape during the manufacturing process.

The intent of our study was to determine whether there is any significant difference between the signal transfer capabilities and conductivities of the textile transmission lines when they are subjected to different welding parameters. Therefore, to limit the number of experimental trials while setting up the manufacturing process in order to find the optimal working process parameters for the fabric samples, firstly pre-work on samples was carried out to see that the application procedure and then different welding parameters within a determined working interval were chosen according to the proposed experimental plan, as shown in Figure 3. In detail, welding parameters have been mainly chosen according to welding tapes and thermoplastic fabrics. Initially, recommended welding conditions for the usage of the hot air welding machine according to the technical sheets of welding tapes were used, since welding tapes with adhesive layers have a considerable effect 
Table I. The properties of the conductive yarns used as transmission lines

\begin{tabular}{llllrlr}
\hline $\begin{array}{l}\text { Conductive } \\
\text { yarn no }\end{array}$ & Material type & $\begin{array}{l}\text { Weight } \\
(\mathrm{g} / \mathrm{m})\end{array}$ & $\begin{array}{l}\text { Diameter } \\
(\mu \mathrm{m})\end{array}$ & $\begin{array}{l}\text { Count } \\
(\mathrm{dtex})\end{array}$ & $\begin{array}{l}\text { Yarn twist } \\
\left(\mathrm{m}^{-1}\right)\end{array}$ & $\begin{array}{l}\text { Linear } \\
\text { resistance }(\Omega / \mathrm{m})\end{array}$ \\
\hline YI & $100 \%$ stainless steel & 0.13 & 315 & $90 \times 1$ & 149 & $<75$ \\
Y2 & $100 \%$ stainless steel & 0.19 & 464 & $90 \times 2$ & 207 & $<35$ \\
Y3 & $100 \%$ stainless steel & 0.82 & 632 & $275 \times 3$ & 224 & $<10$ \\
Y4 & $99 \%$ silver-coated nylon & 0.0045 & 142 & $30 \times 1$ & 125 & $<2000$ \\
Y5 & $99 \%$ silver-coated nylon & 0.044 & 230 & $33 \times 1$ & 174 & $<1350$ \\
Y6 & $99 \%$ silver-coated nylon & 0.0113 & 377 & $70 / 34 \times 1$ & 130 & $<420$ \\
Y7 & $99 \%$ silver-coated nylon & 0.125 & 764 & $235 / 34 \times 4$ & 349 & $<50$ \\
\hline
\end{tabular}

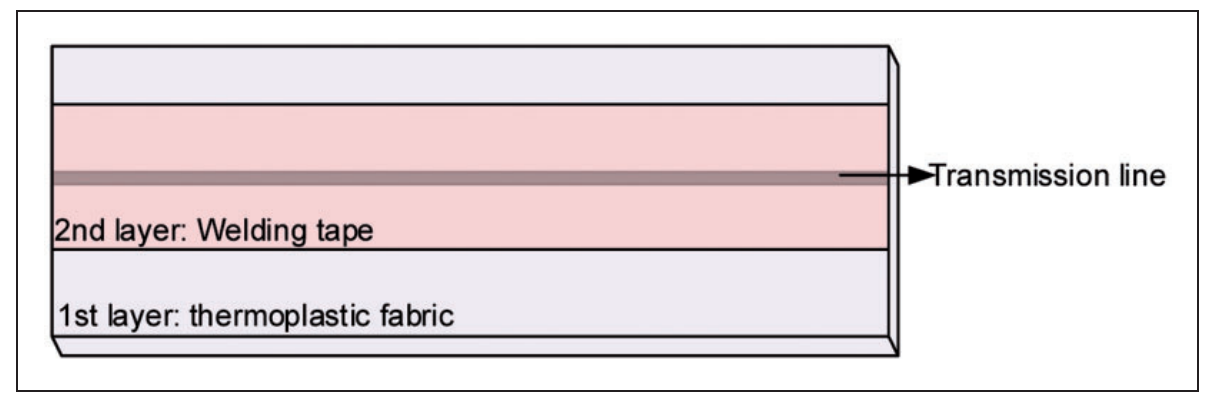

Figure 2. Schematic diagram for e-textile structure with a transmission line.

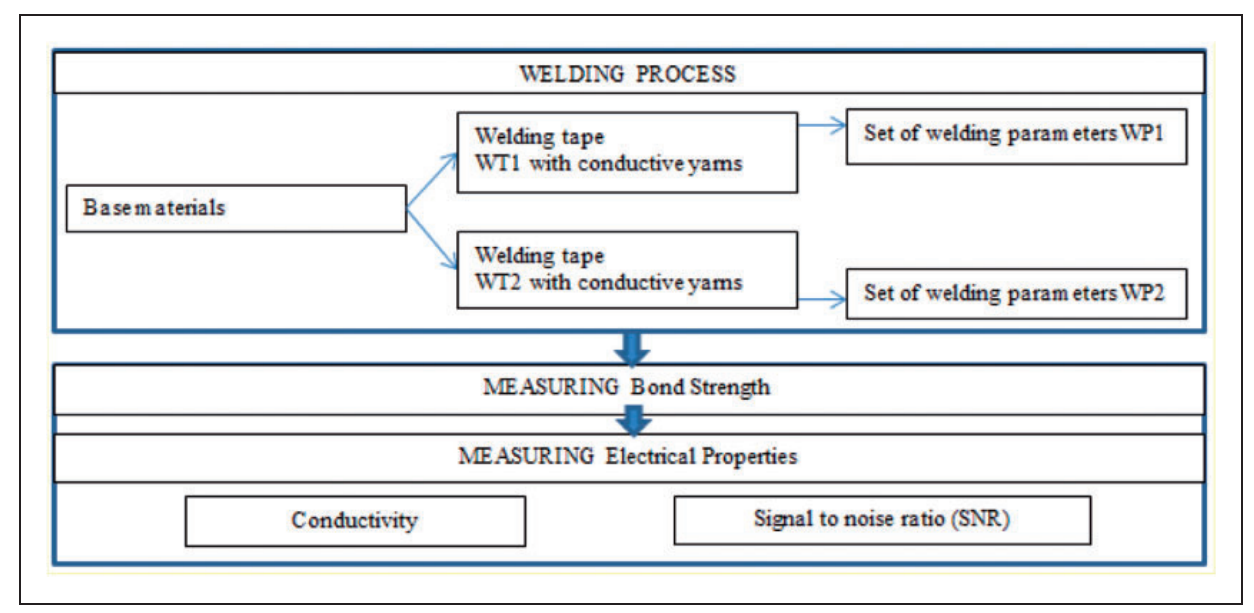

Figure 3. Experiment plan.

on the set-up of welding process parameters. Hence, we tested the initial parameters with an experienced technical person, and then we decided the appropriate welding process parameters for our samples.

As a result, the welding parameters, such as welding pressure, welding speed and welding temperature, were adjusted according to the base fabric used and types of welding tapes. The welding pressure, pressure of hot air and wheel pressure of blow were set up to $0.65,0.07$ and $0.25 \mathrm{MPa}$, respectively, during the manufacturing process of all samples, while temperature and sealing speed were arranged at two different levels for each welding tape, as shown in Table 2 . The reason for keeping the welding pressure, pressure of hot air and wheel pressure of blow as constants is based on experimental experiences as well as the experts' knowledge and the recommendations of those who use hot air welding technologies.

Some of textile transmission line samples manufactured via a hot air seam welding machine are shown in Figure 4. As seen in the figure, the conductive yarns used as the transmission line to satisfy signal 
Table 2. Hot air welding parameters for manufacturing e-textile transmission lines

\begin{tabular}{|c|c|c|c|c|c|c|c|}
\hline $\begin{array}{l}\text { Welded } \\
\text { tapes }\end{array}$ & $\begin{array}{l}\text { Welded } \\
\text { process }\end{array}$ & $\begin{array}{l}\text { Welding } \\
\text { parameters }\end{array}$ & $\begin{array}{l}\text { Temperature } \\
\left({ }^{\circ} \mathrm{C}\right)\end{array}$ & $\begin{array}{l}\text { Sealing speed } \\
(\mathrm{m} / \mathrm{min})\end{array}$ & $\begin{array}{l}\text { Pressure } \\
(\mathrm{MPa})\end{array}$ & $\begin{array}{l}\text { Pressure of } \\
\text { hot air }(\mathrm{MPa})\end{array}$ & $\begin{array}{l}\text { Wheel pressure } \\
\text { of blow (MPa) }\end{array}$ \\
\hline \multirow[t]{4}{*}{ WTI } & \multirow[t]{4}{*}{ WPI } & TIVI & 180 & 1.5 & \multirow[t]{4}{*}{0.65} & \multirow[t]{4}{*}{0.07} & \multirow[t]{4}{*}{0.25} \\
\hline & & TIV2 & 180 & 3 & & & \\
\hline & & $\mathrm{T} 2 \mathrm{VI}$ & 200 & 1.5 & & & \\
\hline & & $\mathrm{T} 2 \mathrm{~V} 2$ & 200 & 3 & & & \\
\hline \multirow[t]{4}{*}{ WT2 } & \multirow[t]{4}{*}{ WP2 } & T3V3 & 280 & 1.5 & \multirow[t]{4}{*}{0.65} & \multirow[t]{4}{*}{0.07} & \multirow[t]{4}{*}{0.25} \\
\hline & & T3V4 & 280 & 2.5 & & & \\
\hline & & $\mathrm{T} 4 \mathrm{~V} 3$ & 300 & 1.5 & & & \\
\hline & & T4V4 & 300 & 2.5 & & & \\
\hline
\end{tabular}

T: Temperature; V: Velocity.

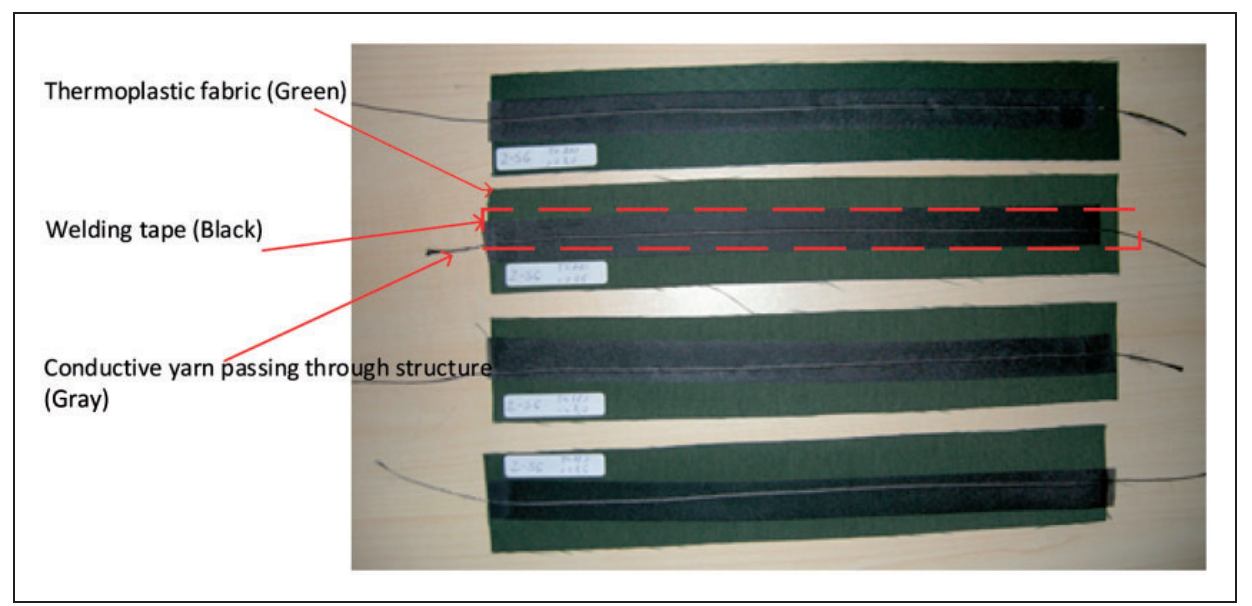

Figure 4. The hot air welded transmission line samples with conductive yarn $Y 3$, welding tape WT2 and welding process WP2 (thermoplastic fabric (green): $60 \%$ polyethylene terephthalate and $40 \%$ cotton; color online only).

transmission were hidden within the two-layered structure without any undulation.

After the welding process, the samples were stabilized for 24 hours within an air conditioned climate chamber before testing.

\section{Testing of welded textile transmission lines}

In this study, since the bonding strength of the welded fabric structure is so important before all quality and performance aspects, it was initially tested and evaluated according to standard DIN 54310. In order to test the electrical properties of the textile transmission lines, conductivity measurements and signal analysis with signal-to-noise ratio (SNR) calculations were carried out, since the conductivity and signal transmission qualities are the main relevant parameters for the functioning of e-textiles.

Conductivity measurements. A Keithley ${ }^{\circledR}$ multimeter was used to measure the conductivities of the yarns. The linear resistances of yarns were calculated in ohms per meter $(\Omega / \mathrm{m})$ by taking measurements along the length of yarn samples. The linear resistances of the yarns were measured according to the four-point probe method and each measurement was repeated three times. All the tests were carried out under laboratory conditions $\left(20^{\circ} \mathrm{C}\right.$ and $65 \%$ relative humidity).

Signal analysis and signal-to-noise ratio calculations. During the measurements, a TECO-PIC (from TEKOElektronik Ltd.) experimental kit was initially connected to e-fabric samples to satisfy electrical signal generation over the transmission lines. Then, an oscilloscope (from TEKTRONIX Inc., TDS 2012B) was connected to the transmission lines of the samples in order to observe electrical signal waveforms. Afterwards, the obtained signals over the transmission lines were directly transferred and recorded in the computer for signal analysis. The diagram for the signal measurements is given in Figure 5.

The signals extracted from the oscilloscope were in their raw form, meaning in an unprocessed state, and 


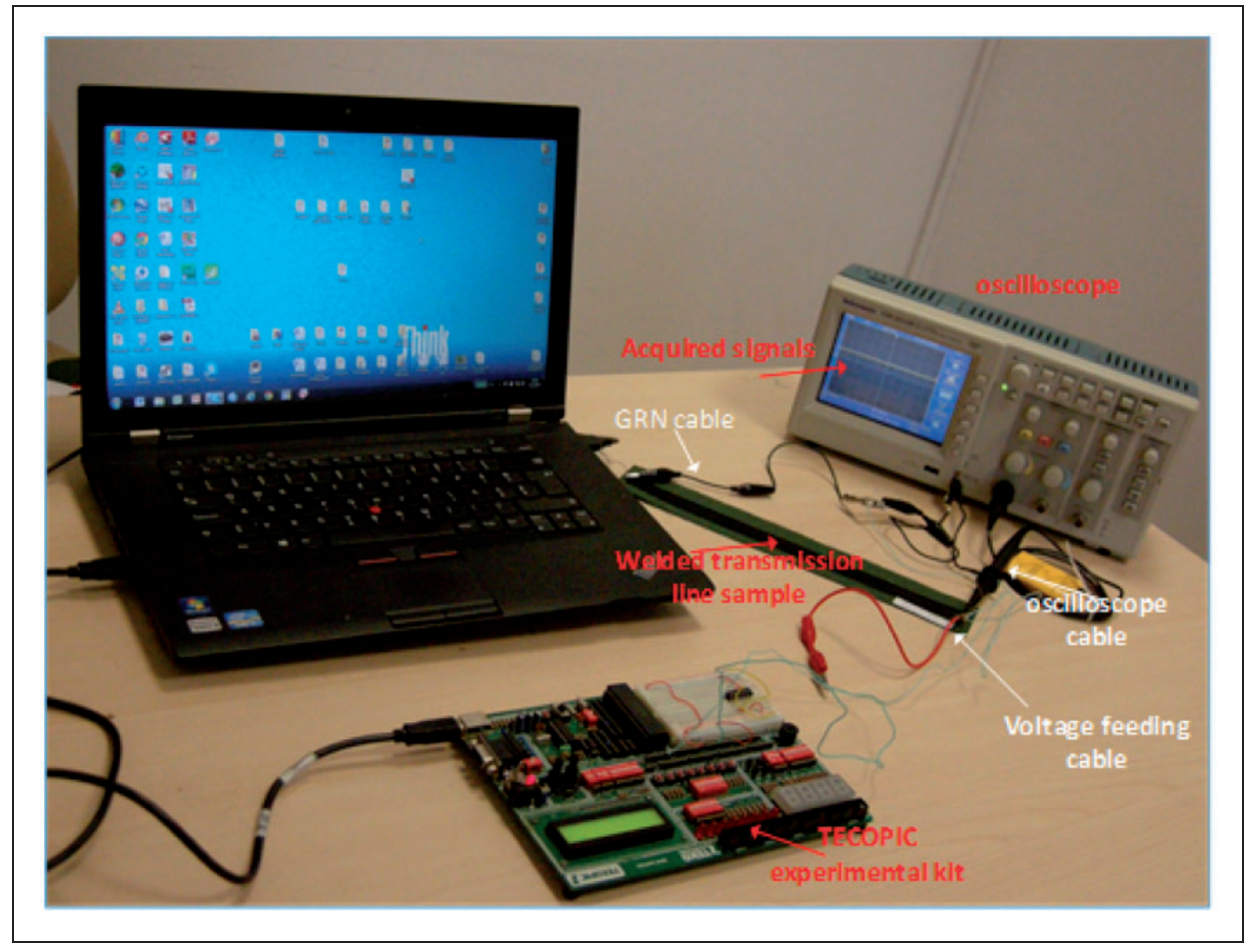

Figure 5. Signal measurements over transmission lines.

included substantial electrical noise. In order to make any reasonable comparison of the signal transferring capabilities of those e-fabric samples subjected to different sets of welding processes, the recorded signals were analyzed using MATLAB $^{\circledR}$ R2010b software (from MathWorks, Inc.), and their SNR values were calculated.

\section{Signal-to-noise calculation}

Essentially, the SNR is the ratio of the signal of interest (signal power) to undesirable signal (noise power). ${ }^{27}$ The SNR can be estimated by calculating the ratio of signal power to noise power. In our study, once the signal was recorded, noise level (unwanted signal) and noise amplitude were determined by signal processing in MATLAB ${ }^{\circledR}$ (from MathWorks, Inc.). Since the signal and noise were measured in the same impedance, the SNR was obtained by calculating the square of the amplitude ratio, where $A$ is the root mean square amplitude in equation (1)

$$
\mathrm{SNR}=\left(\frac{A_{\text {signal }}}{A_{\text {noise }}}\right)^{2}
$$

Generally, the SNRs are expressed in logarithmic decibel scale. In electronics, the decibel is a convenient way for engineers to describe the input-to-output ratios of either power or voltages. Therefore, in order to quantify the signal qualities of each sample, the $\mathrm{SNR}_{\mathrm{dB}}$ value of each sample was calculated by using equations (2) and (3) ${ }^{28}$

$$
\begin{gathered}
\mathrm{SNR}_{\mathrm{dB}}=10 \log _{10}\left(\frac{P_{\text {signal }}}{P_{\text {noise }}}\right)=P_{\text {signal }, \mathrm{dB}}-P_{\text {noise } \mathrm{dB}} \\
\mathrm{SNR}_{\mathrm{dB}}=10 \log _{10}\left(\frac{A_{\text {signal }}}{A_{\text {noise }}}\right)^{2}=20 \log _{10}\left(\frac{A_{\text {signal }}}{A_{\text {noise }}}\right)
\end{gathered}
$$

A higher SNR value is indicative of better signal quality and less noise, which is preferred. For each calculation, 2500 data were taken for one signal transfer. From this raw data, mean SNRs of each sample belonging to each conductive yarn type were calculated for each stage of the welding process. The results of signal analyses were used to evaluate the signal transference capabilities of the samples due to the conductive yarn types and welding parameters.

\section{Statistical analysis}

The two-way ANOVA was used for verifying the effects of temperature in the hot air welding process for each welding tape on the linear resistances and SNR values of the welded samples. The verification of null hypothesis was $\mathrm{H}_{0}: \sigma_{1}^{2}=\sigma_{0}^{2}$, which assumes that there were no significant differences between the groups analyzed. The $F$-test with a confidence level $\alpha=0.05$ was used for 
the confirmation of the null hypothesis. ${ }^{29}$ The number of measurement repetitions was chosen according to previous preliminary research work. ${ }^{30}$

\section{Results and discussion}

\section{Bonding strength results}

The obtained results of the measured bonding strengths according to the selected welding parameters are shown in Table 3.

It can be seen from the results that welded transmission lines at lower temperature and high sealing speed have lower bonding strengths. The observed phenomenon was clearly presented for welded transmission lines welded with welding tape WT2. At both selected welding temperatures $\left(T=280^{\circ} \mathrm{C}\right.$ and $\left.300^{\circ} \mathrm{C}\right)$ the bonding strengths were higher when the samples were exposed to slower welding processes (sealing speed: $1.5 \mathrm{~m} / \mathrm{min}$ ). The bonding strengths of the welded transmission lines were valid as regular measurements if the fabric and welded tape were divided smoothly without tearing the fabric or the welded tape. It can be seen that the bonding strengths of the welded transmission lines had values within the range of $12.75-17.55 \mathrm{~N} / 5 \mathrm{~cm}$ for welding tape WT2. Apart from this, the regular measurements of the bonding strengths of the manufactured welding transmission line samples with welding tape WT1 were obtained only at temperatures of $180^{\circ} \mathrm{C}$. However, at temperature $200^{\circ} \mathrm{C}$, the separation bonding strength measurements were not seen between the fabric and welding tape; it was observed between the first layer (knitted layer) and the second layer (waterproof film layer) instead of the third layer, as noted in Table 3. In the mentioned case, the waterproof

Table 3. Bonding strength results

\begin{tabular}{|c|c|c|c|c|}
\hline $\begin{array}{l}\text { Welding } \\
\text { tape }\end{array}$ & $\begin{array}{l}\text { Temperature } \\
\left({ }^{\circ} \mathrm{C}\right)\end{array}$ & $\begin{array}{l}\text { Sealing } \\
\text { speed } \\
(\mathrm{m} / \mathrm{min})\end{array}$ & $\begin{array}{l}\text { Pressure } \\
(\mathrm{MPa})\end{array}$ & $\begin{array}{l}\text { Bond strength } \\
(\mathrm{N} / 5 \mathrm{~cm})\end{array}$ \\
\hline \multirow[t]{4}{*}{ WTI } & 180 & 1.5 & 0.65 & 21.98 \\
\hline & 180 & 3 & 0.65 & 19.2 \\
\hline & 200 & 1.5 & 0.65 & $\begin{array}{l}17.75 \\
\text { (No regular } \\
\text { bond strength) }\end{array}$ \\
\hline & 200 & 3 & 0.65 & $\begin{array}{l}16.48 \\
\text { (No regular } \\
\text { bond strength) }\end{array}$ \\
\hline \multirow[t]{4}{*}{ WT2 } & 280 & 1.5 & 0.65 & 17.55 \\
\hline & 280 & 2.5 & 0.65 & 14.13 \\
\hline & 300 & 1.5 & 0.65 & 16.4 \\
\hline & 300 & 2.5 & 0.65 & 12.75 \\
\hline
\end{tabular}

film was totally stuck on the fabric. Therefore, special attention should be paid to the joining of this welding tape WT1consisting of three layers during the manufacturing of textile transmission lines.

Since the welding technology is being performed in a very similar manner to fusing technology, unpredictable interactions can be expected due to the welding process parameters on bond strength properties of e-textile transmission lines after the welding process. In a study on fusing, the results indicated that with the same fusing parameter, even if the same fabrics are fused with identical fusing interlining, the bond strength results as well as other mechanical and physical properties of fused panels will change. ${ }^{31}$ Irrespective of variances among the gained results, the bond strength analysis is sufficient to show the trend of influence of welding parameters on bond strength.

The join between welding tape and fabric, as well as the join between layers of welding tape, should be adjusted from the bonding strength point of view when hot air welding parameters are planned. In that way, the conductive yarns will be better protected, safely hidden and also protected against environmental influences. This is also very important for security during the usages of smart garments.

\section{Conductivity results}

Figures 6 and 7 illustrate some of the changes in the linear resistances of conductive yarns when subjected to welding processes. It is apparent from the figures that as the temperature increased, the linear resistances of the conductive yarns generally decreased for both stainless steel and silver-coated polyamide yarns when compared to their original linear resistance values. For instance, the linear resistance of stainless steel yarn no. 1 decreased from 75 to $69 \Omega / \mathrm{m}$ (Table 4 ) and from 75 to $66 \Omega / \mathrm{m}$ (Table 5) with welding tape WT1 and welding tape WT2, respectively. However, the more dramatic decrease was observed with silver-coated polyamide yarn no.4 and yarn no.5, which had high linear resistance values of 2000 and $1350 \Omega / \mathrm{m}$, respectively (see Tables 4 and 5).

As the temperature increased, only the conductivity of the welded conductive yarn no.3, which has a linear resistance value of less than $10 \Omega / \mathrm{m}$, stayed almost at the same value, as shown in Tables 4 and 5 .

In the continuous mode, the sealing speed is taken as weld (sealing) time because the exposure length to the hot air is constant at any given time. As the sealing speed decreased or the exposure time increased, the linear resistances of both the stainless steel conductive yarns and silver-plated polyamide yarns generally decreased also, as seen in Tables 4 and 5 . As the exposure time increases, the amount of energy transmission to the 


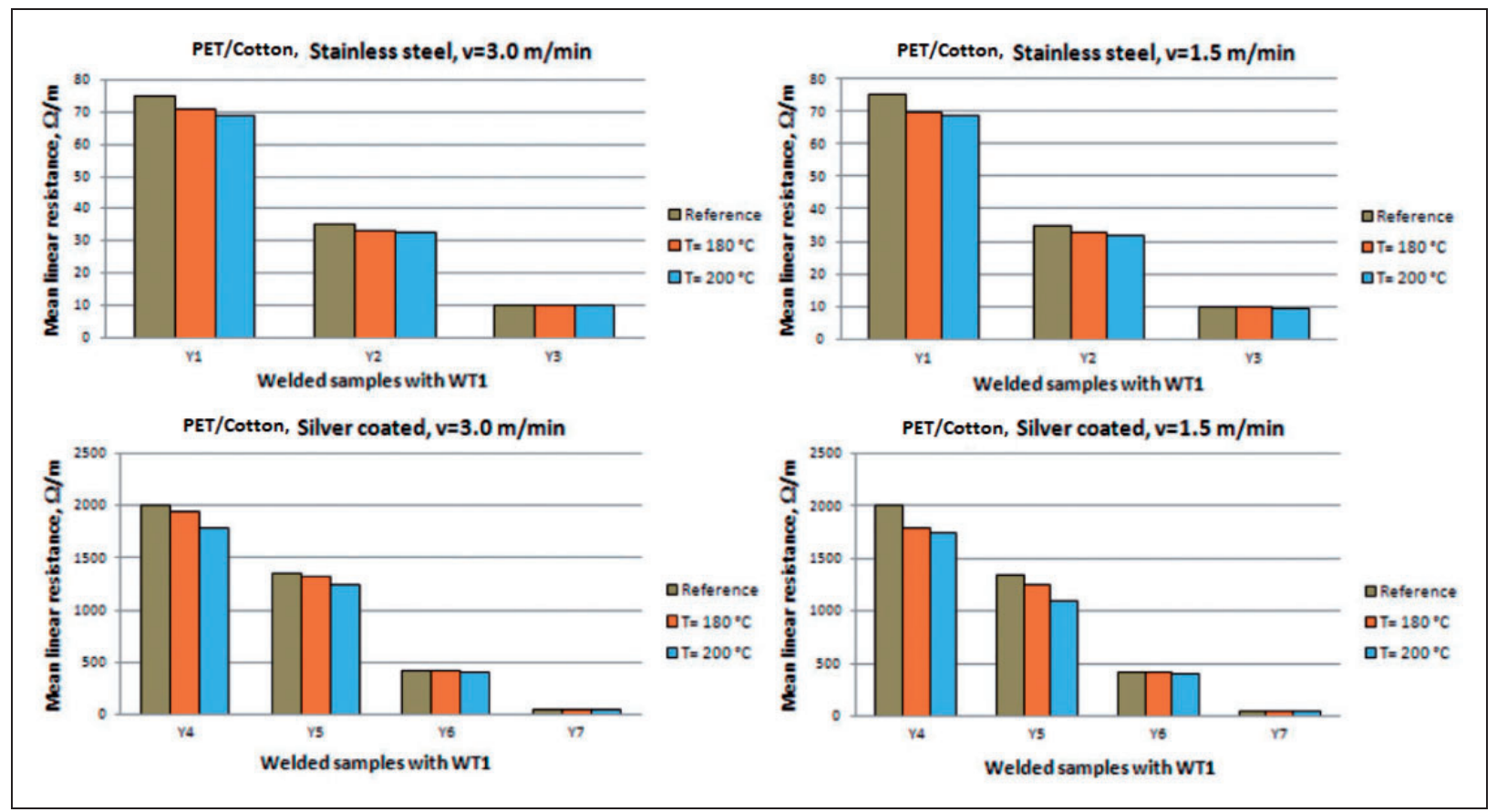

Figure 6. Changes in mean linear resistances of welded samples with WTI due to the applied temperature. PET/Co: Polyester/Cotton.

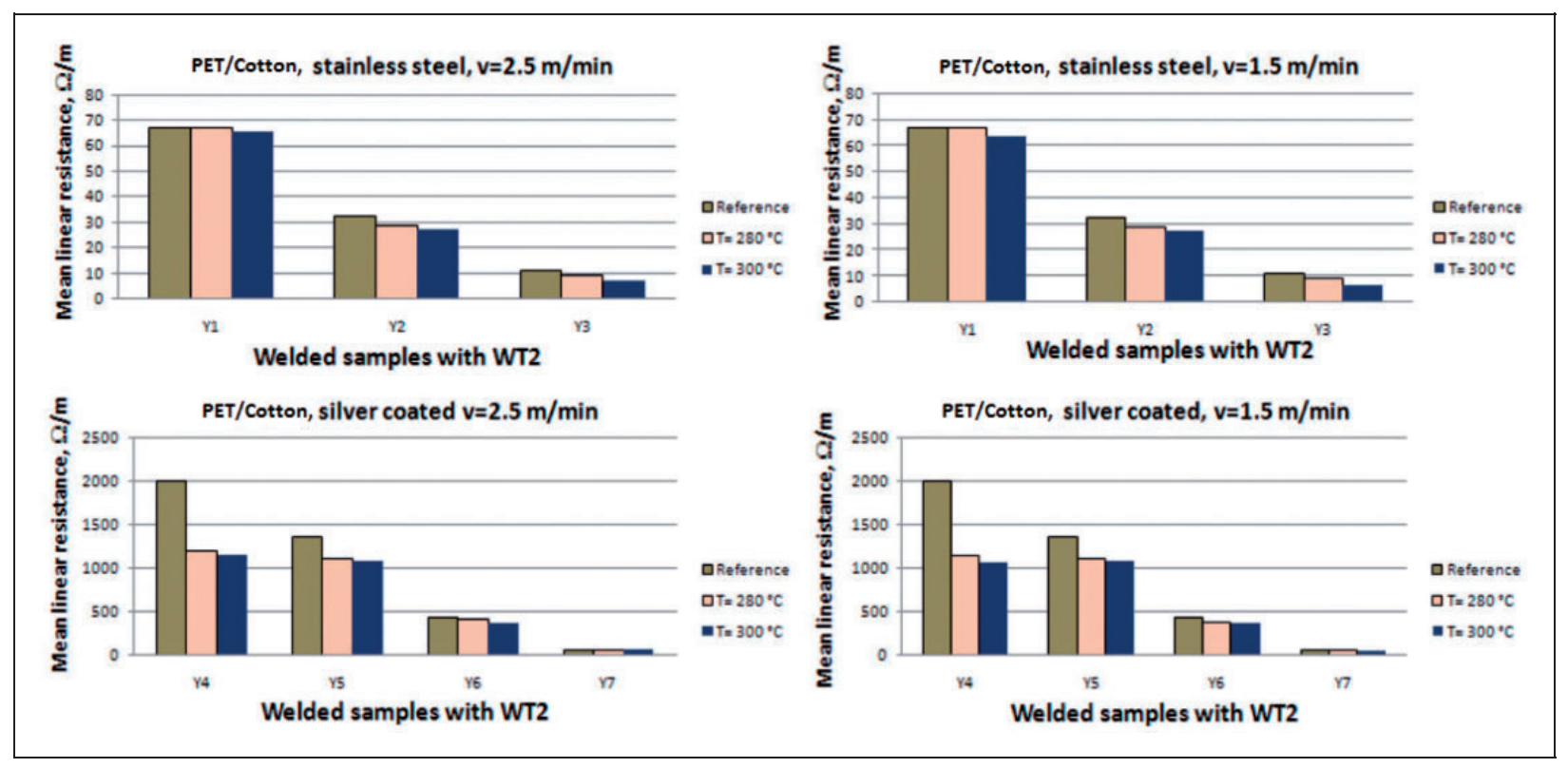

Figure 7. Change in mean linear resistances of welded samples with WT2 due to the applied temperature. PET/Co: Polyester/Cotton.

fabric increases, thus resulting in exposure of more heat on those conductive yarns positioned between the two layers and this leads to an increase in the electrical conductivities of the welded transmission lines.

Indeed, these trends could be explained by the conductivities of the materials. More specifically, when the weight of the coated conductive yarn is low, this means the amount of coating with conductive material is relatively less, due to the lower amount of conductive material over the surface of the yarn; coated conductive yarn may exhibit higher resistivity, which means a decrease in the conductivity level of the conductive yarn. ${ }^{32,33} \mathrm{In}$ 
Table 4. Mean linear resistances of welded samples with WTI $(\Omega / \mathrm{m})$

\begin{tabular}{lllllllll}
\hline & & $Y 1$ & $Y 2$ & $Y 3$ & $Y 4$ & $Y 5$ & $Y 6$ & Y7 \\
\hline$T=180^{\circ} \mathrm{C}$ & Reference $^{\mathrm{a}}$ & 75.00 & 35.00 & 10.00 & 2000.00 & 1350.00 & 420.00 & 50.00 \\
& $v=3.0 \mathrm{~m} / \mathrm{min}$ & 70.89 & 33.36 & 10.09 & 1937.78 & 1312.22 & 400.49 & 49.66 \\
& $v=1.5 \mathrm{~m} / \mathrm{min}$ & 69.78 & 32.80 & 9.96 & 1792.22 & 1245.56 & 413.67 & 49.06 \\
$T=200^{\circ} \mathrm{C}$ & Reference $^{\mathrm{a}}$ & 75.00 & 35.00 & 10.00 & 2000.00 & 1350.00 & 420.00 & 50.00 \\
& $v=3.0 \mathrm{~m} / \mathrm{min}$ & 69.78 & 32.80 & 9.96 & 1787.78 & 1245.56 & 418.44 & 48.26 \\
& $v=1.5 \mathrm{~m} / \mathrm{min}$ & 68.67 & 31.76 & 9.58 & 1736.67 & 1101.11 & 401.66 & 47.88 \\
\hline
\end{tabular}

${ }^{a}$ Values indicate the values taken from Table I, which represent the real linear resistance values of yarns.

Table 5. Mean linear resistances of welded samples with WT2 $(\Omega / \mathrm{m})$

\begin{tabular}{lllllllll}
\hline & & $Y 1$ & $Y 2$ & $Y 3$ & $Y 4$ & $Y 5$ & Y6 & Y7 \\
\hline$T=280^{\circ} \mathrm{C}$ & Reference $^{\mathrm{a}}$ & 75.00 & 35.00 & 10.00 & 2000.00 & 1350.00 & 420.00 & 50.00 \\
& $v=2.5 \mathrm{~m} / \mathrm{min}$ & 67.33 & 28.56 & 9.22 & 1197.78 & 1107.78 & 404.67 & 46.89 \\
& $v=1.5 \mathrm{~m} / \mathrm{min}$ & 66.78 & 28.44 & 7.78 & 1135.56 & 1098.89 & 372.78 & 46.56 \\
$T=300^{\circ} \mathrm{C}$ & Reference $^{\mathrm{a}}$ & 75.00 & 35.00 & 10.00 & 2000.00 & 1350.00 & 420.00 & 50.00 \\
& $v=2.5 \mathrm{~m} / \mathrm{min}$ & 68.56 & 30.53 & 9.51 & 1156.67 & 1081.11 & 367.44 & 45.78 \\
& $v=1.5 \mathrm{~m} / \mathrm{min}$ & 66.62 & 29.80 & 9.49 & 1056.67 & 1087.78 & 369.22 & 46.56 \\
\hline
\end{tabular}

${ }^{a}$ Values indicate the values taken from Table I, which represent the real linear resistance values of yarns.

our case for instance, yarn no.4 is the silver-coated polyamide yarn with lower weight compared to other conductive yarns and its conductivity level is also lower than others with a higher linear resistance value of $2000 \Omega / \mathrm{m}$ (see Table 1). When it is subjected to heat at temperatures greater than $180^{\circ} \mathrm{C}$ within the hot air welding process, since its conductivity is low it is considerably influenced (see Figure 8).

However, the ANOVA showed that the influences of welding parameters on the linear resistances of the welded samples with welding tape WT1 and welding tape WT2 were statistically insignificant (Tables 6 and 7). Thus, it can be concluded that the analyzed hot air welding processes resulted in changes of the linear resistances of the samples when using welding tapes WT1 and WT2 but did not have a significant impact.

Indeed, from the point of view of e-textiles, the conductive yarns with linear resistance of less than $200 \Omega / \mathrm{m}$ are generally preferred for signal transmission. Therefore, it can be said that the obtained results based on conductivity are really promising for the manufacturing of e-textile transmission lines via hot air welding technology.

\section{Signal-to-noise ratio results}

Figures 9 and 10 show the SNRs of the welded transmission lines according to the applied velocities. It is evident from the figures that after the welding process

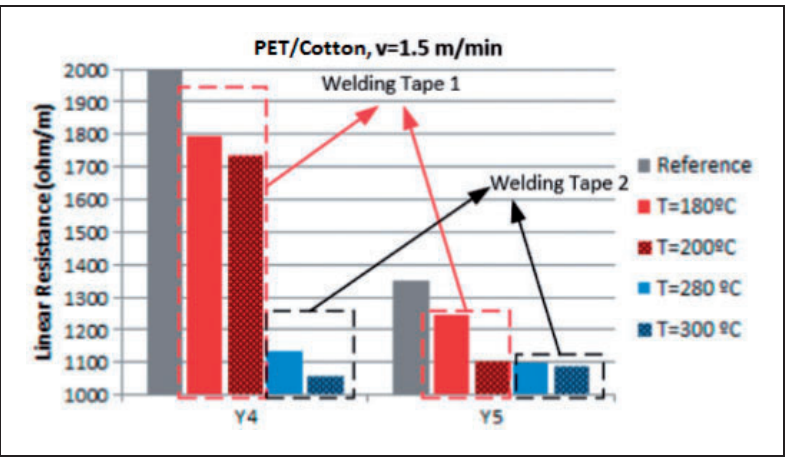

Figure 8. Linear resistance changes in yarn no. 4 and yarn no.5 due to increasing temperature.

PET/Co: Polyester/Cotton.

the SNR values of the samples generally increased. In particular for welding tape WT1, when the applied sealing speed increased from $v=1.5 \mathrm{~m} / \mathrm{min}$ to $v=3.0 \mathrm{~m} / \mathrm{min}$, the signal qualities of the transmission lines increased. In addition, it was also found that for welding tape WT1 when the applied temperature increased, the SNRs of the welded samples also increased. However, increased temperature during the welding process for welding tape WT2 led to different obtained SNR values. For instance, when the temperature increased from $T=280^{\circ} \mathrm{C}$ to $T=300^{\circ} \mathrm{C}$, yarn no. 6 showed a decrease, whereas yarn no.3 showed an increase in SNR values at $v=1.5 \mathrm{~m} / \mathrm{min}$ (Figure 10). 
Table 6. Analyses of the variances regarding the influences of welding parameters on the linear resistances of the welded samples with welding tape WTI $\left(\alpha=0.05, F_{\text {tab }}=3.55 ; d f_{1}, d f_{2}=2.18\right)$

\begin{tabular}{|c|c|c|c|c|c|c|}
\hline \multirow[b]{2}{*}{ Welding process } & \multicolumn{2}{|l|}{ Sum of squares } & \multicolumn{2}{|l|}{ Mean square } & \multirow[b]{2}{*}{$F_{\mathrm{cal}}$} & \multirow[b]{2}{*}{ Significance } \\
\hline & Between groups & Within groups & Between groups & Within groups & & \\
\hline$T=180^{\circ} \mathrm{C}$ & $1.45 \mathrm{E}+08$ & $2.53 E+09$ & $7.258 e+007$ & $1.404 e+008$ & 0.5169 & No \\
\hline$T=200^{\circ} \mathrm{C}$ & $1.14 \mid e+008$ & $9.201 \mathrm{e}+010$ & $5.703 e+007$ & $5.112 e+009$ & 0.1116 & No \\
\hline
\end{tabular}

Table 7. Analyses of the variances regarding the influences of welding parameters on the linear resistances of the welded samples with welding tape WT2 $\left(\alpha=0.05, F_{\text {tab }}=3.55 ; d f_{1}, d f_{2}=2.18\right)$

\begin{tabular}{llllllll}
\hline & \multicolumn{2}{l}{ Sum of squares } & & \multicolumn{2}{l}{ Mean square } & & \\
\cline { 2 - 3 } Welding process & Between groups & Within groups & & Between groups & Within groups & $F_{\text {cal }}$ & Significance \\
\hline$T=280^{\circ} \mathrm{C}$ & 131,275 & $6,969,000$ & & 65,637 & 387,142 & 0.1695 & No \\
$T=300^{\circ} \mathrm{C}$ & 144,038 & $6,781,000$ & & 72,019 & 376,697 & 0.1912 & No \\
\hline
\end{tabular}

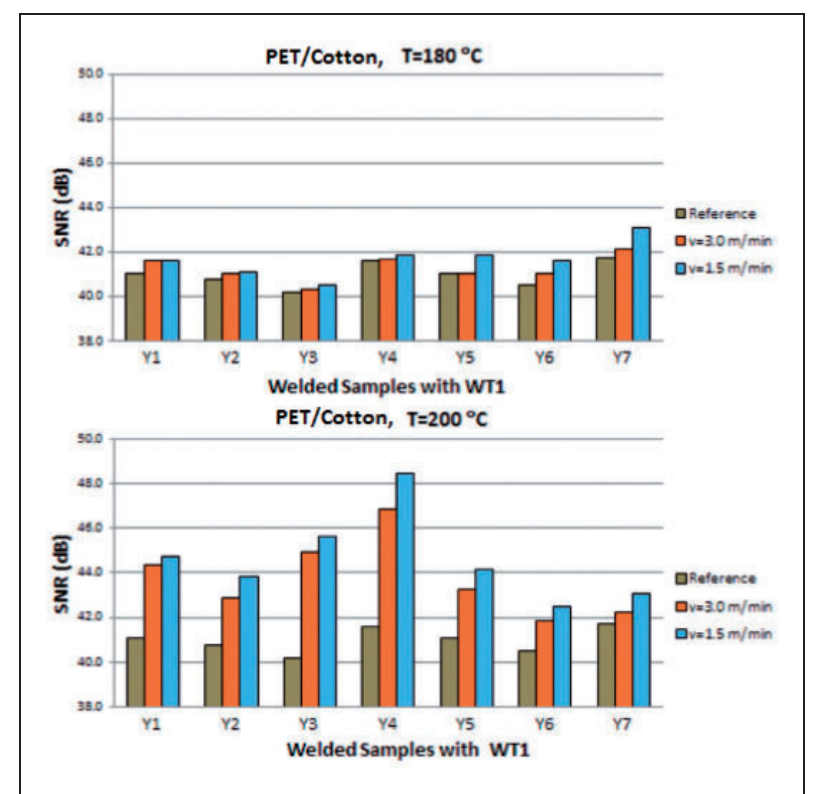

Figure 9. Comparison between the signal-to-noise ratio (SNR) values of welded samples with welding tape WTI when $v=3.0 \mathrm{~m} / \mathrm{min}$ and $v=1.5 \mathrm{~m} / \mathrm{min}$.

PET/Co: Polyester/Cotton.

Moreover, it can be seen that the higher SNR values were observed with transmission lines, including silvercoated polyamide yarn no.4, for both welding tapes, which had higher linear resistance values and lower weights when compared to other conductive yarns.

In general, with respect to Figures 9 and 10 it can be concluded that after welding, the process transmission lines showed better signal transference capabilities compared to their reference values. This can probably be explained by the shielded electrical cable principle, as it is a known fact that shielded cable conducts an

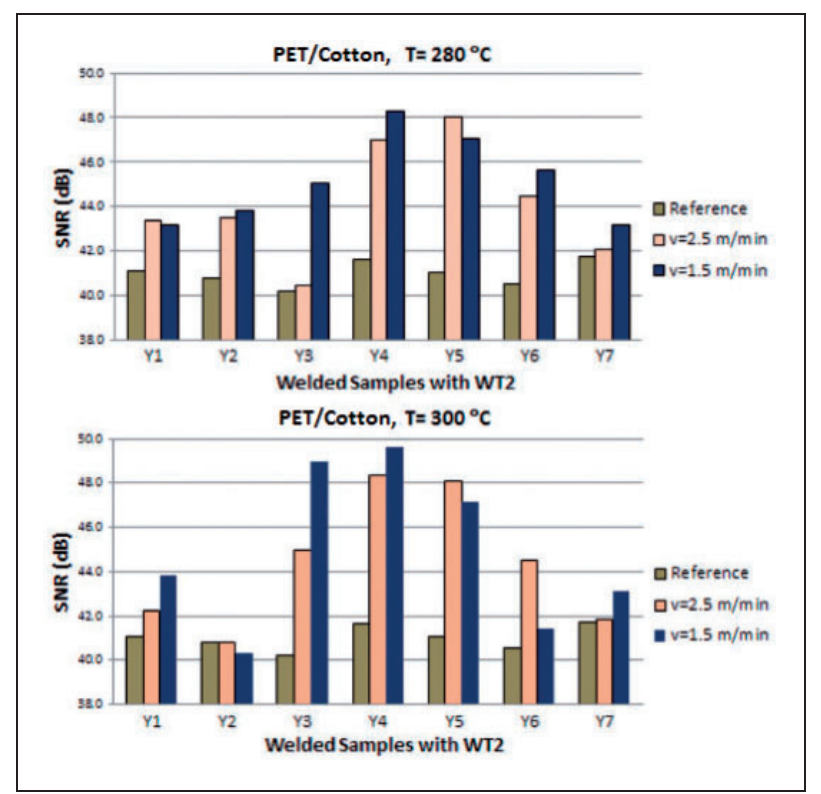

Figure 10. Comparisons between the signal-to-noise ratio (SNR) values of the welded samples with welding tape WT2 when $v=2.5 \mathrm{~m} / \mathrm{min}$ and $v=1.5 \mathrm{~m} / \mathrm{min}$.

$\mathrm{PET} / \mathrm{Co}$ : Polyester/Cotton.

electrical signal using an inner conductor wrapped within an insulated layer. Thus, the signal transmission inside the cable is protected by an outer shell from the electric and magnetic fields outside that cause interference to signals inside the cable. ${ }^{34}$ In our case, the coated conductive fibers positioned between the PET/Co fabric and the membrane were held together by adhesion. Therefore, the outer surface of the conductive yarn was hidden within the structure and was wrapped by bonds of membrane and PET/Co fabric together, where it behaves like a shielded cable with a bonded outer 
Table 8. Analyses of the variances regarding the influence of sealing speed at some temperature on the signal-to-noise ratio values of the welded samples with welding tape WTI $\left(\alpha=0.05, F_{\text {tab }}=3.55 ; d f_{1}, d f_{2}=2\right.$. I8)

\begin{tabular}{|c|c|c|c|c|c|c|}
\hline \multirow[b]{2}{*}{ Welding process } & \multicolumn{2}{|l|}{ Sum of squares } & \multicolumn{2}{|l|}{ Mean square } & \multirow[b]{2}{*}{$F_{\text {cal }}$} & \multirow[b]{2}{*}{ Significance } \\
\hline & Between groups & Within groups & Between groups & Within groups & & \\
\hline$T=180^{\circ} \mathrm{C}$ & 1.591 & 7.701 & 0.7956 & 0.4278 & 1.860 & No \\
\hline$T=200^{\circ} \mathrm{C}$ & 49.71 & 44.21 & 24.85 & 2.456 & 10.12 & Yes \\
\hline
\end{tabular}

Table 9. Analysis of the variance regarding the influence of sealing speed at some temperature on signal-to-noise ratio values of welded samples with welding tape WT2 $\left(\alpha=0.05, F_{\text {tab }}=3.55 ; d f_{1}, d f_{2}=2.18\right)$

\begin{tabular}{lllllllll}
\hline & \multicolumn{2}{l}{ Sum of squares } & & & Mean square & & & \\
\cline { 2 - 3 } Welding process & Between groups & Within groups & & Between groups & Within groups & & $F_{\text {cal }}$ & Significance \\
\hline$T=280^{\circ} \mathrm{C}$ & 65.97 & 67.40 & & 32.98 & 3.744 & & 8.809 & Yes \\
$T=300^{\circ} \mathrm{C}$ & 63.17 & 136.4 & & 31.59 & 7.579 & & 4.168 & Yes \\
\hline
\end{tabular}

shell. In this way, the conductive yarns hidden within the structure may be protected from the noise around and, thus, their signal transferring capabilities may show an increase.

In addition to these findings, ANOVAs also showed that the influences of welding parameters on the SNR values of the welded samples with welding tape WT2 were statistically significant (Tables 8 and 9). Moreover, with welding tape WT1 at $T=200^{\circ} \mathrm{C}$, the variations in sealing speed also influenced the SNR values of the welded samples significantly. Based on these results, it can be concluded that the choice of welding tapes with conductive yarns can cause significant changes in the signal qualities of the welded textile transmission lines. This property, obtained as a result of the welding process, makes the welded transmission lines a good choice for carrying signals.

\section{Conclusions}

This paper presented the use of hot air welding technology in order to develop textile transmission lines for e-textile applications. The proposed transmission lines are two-layered fabrics composed of one insulating layer to protect and to hide the conductive yarn within the textile structure from various environmental effects. Different conductive yarn types with different linear resistance values were used to form seams at different welding temperatures and speeds.

The obtained results based on conductivity and signal transference capability are promising for the manufacturing of e-textile transmission lines via hot air welding technology. For all transmission line constructions, welded seams were produced with adequate electrical conductivity properties at certain combinations of parameters. However, it can be concluded that the choice of welding parameters, depending on the materials used for the formations of textile transmission lines, is extremely important for obtaining good electro-conductive properties. In addition, welding tapes and thermoplastic materials play an important role during the set-up of welding process parameters. It was also found that welding tapes with conductive yarns can cause a variety of changes in the signal qualities of welded textile transmission lines.

Understanding those hot air welding parameters that influence the electrical properties of a textile transmission line will make it possible to construct reliable and durable transmission lines while preserving the textiles' aspects. Transmission lines including welding tapes with high signal quality and reliable linear resistance enable new options of interconnection for wearable computing applications, smart clothing and interactive e-textile structures. Welding with waterproof welding tapes will additionally enhance the durability of signal lines by protecting them from probable short circuits and water contact. Thus, they may have a high potential application in e-textile circuit designs. However, the hot air welding parameters need to be carefully controlled to avoid excessive melting and polymer degradation.

\section{Declaration of conflicting interests}

The authors declared no potential conflicts of interest with respect to the research, authorship and/or publication of this article.

\section{Funding}

The authors disclosed receipt of the following financial support for the research, authorship, and/or publication of this article: This project has received funding from the European 
Union's Horizon 2020 research and innovation programme under the Marie Skłodowska-Curie grant agreement No 644268. In addition, this research work was supported by TUBITAK (The Scientific \& Technological Research Council of Turkey) Project no. 214M405 and BIDEB (Science Fellowships \& Grant Programs Department), 2221 - Fellowships for Visiting Scientists and Scientists on Sabbatical Leave, for the period 2014-2015.

\section{References}

1. Lesnikowski J and Tokarska M. Modeling of selected electric properties of textile signal lines using neural networks. Text Res J 2014; 84: 290-302.

2. Cottet D, Grzyb J, Kirstein T, et al. Electrical characterization of textile transmission lines. IEEE Trans Adv Packag 2003; 26: 182-186.

3. Leśnikowski J. Textile transmission lines in the modern textronic clothes. Fibres Text East Eur 2011; 19: 89-93.

4. Odhiambo SA, Gilbert DM, Hertleer C, et al. Discharge characteristics of poly(3.4-ethylene dioxythiophene): poly(styrenesulfonate) (PEDOT:PSS) textile batteries; comparison of silver coated yarn electrode devices and pure stainless steel filament yarn electrode devices. Text Res $J$ 2014; 84: 347-354.

5. Negru D, Buda CT and Avram D. Electrical conductivity of woven fabrics coated with carbon black particles. Fibres Text East Eur 2012; 1: 53-56.

6. Kim B, Koncar V and Dufour C. Poly- aniline-coated PET conductive yarns: study of electrical. Mechanical and electro-mechanical properties. J Appl Polym Sci 2006; 101: 1252-1256.

7. Gasana E, Westbroek P, Hakuzimana J, et al. Electroconductive textile structures trough electroless deposition of polypyrrole and copper at polyaramide surfaces. Surf Coat Tech 2006; 201: 3547-3551.

8. Vassiliadis S. Electronics and computing in textiles, http://bookboon.com/en/electronics-and-computing-intextiles-ebook (2012, accessed 15 February 2014).

9. Kuhn $\mathrm{HH}$ and Child AD. Electrically conducting textiles. In: Skotheim TA, Elsenbaumer RL and Reynolds JR (eds) Handbook of conducting polymers. New York: Marcel Dekker, 1998, pp.993-1013.

10. Cherenack K and Van Pieterson L. Smart textiles: challenges and opportunities. J Appl Phys 2012; 112: 091301-1-091301-14.

11. Gniotek K, Golebiowski J and Lesnikowski J. Temperature measurements in a textronic fireman suit and visualisation of the results. Fibres Text East Eur 2009; 17: 97-101.

12. Mason A, Wylie S, Korostynska O, et al. Flexible e-textile sensors for real-time health monitoring at microwave frequencies. Int J Smart Sens Intell Syst 2014; 7: 32-48.

13. Arshak $\mathrm{K}$ and Korostynska O. Thin- and thick-film realtime gamma radiation detectors. IEEE Sens $J$ 2005; 5: 574-580.

14. Vervust T, Buyle G, Bossuyt F, et al. Integration of stretchable and washable electronic modules for smart textile applications. $J$ Text Inst 2012; 103: 1127-1138.

15. Violleau E. Ultrasonic welding for composite materials. Compos Mag 2014; 87: 92-95.
16. Prabir J. Assembling technologies for functional garments - an overview. Indian J Text Res 2011; 36: 380-387.

17. Kah P and Martikainen J. Current trends in welding processes and materials: improve in effectiveness. Rev Adv Mater Sci 2012; 30: 189-201.

18. Gaurav D. Advanced technologies for sewing seamless garments, http://www.fibre2fashion.com/industry-article/ technology-industry-article/advanced-technologies-forsewing-seamless-garments/advanced-technologies-forsewing-seamless-garments2.asp (2013, accessed 15 June 2014).

19. Shishoo R. The global textile and clothing industry. Cambridge, UK: Woodhead Publishing Series in Textiles, 2012.

20. Swantko K. Forming a new bond. Fabric trends, http:// www.fabriclink.com/Features/Assets/WeldedGT0804.pdf (2004, accessed 15 June 2014).

21. Jakubčioniene $\breve{Z}$ and MasteikaitèV. Investigation of textile bonded seams. Mater Sci (Medžiagotyra) 2010; 16: 76-79.

22. Seram $N$ and Cabon D. Investigating the possibility of constructing different seam types for clothing using ultrasonic. Int J Cloth Sci Tech 2013; 25: 90-98.

23. Ghosh S and Reddy R. Ultrasonic sealing of polyester and spectra fabrics using thermo plastic properties. Appl Polym Sci 2009; 113: 1082-1089.

24. Shi W and Little T. Mechanisms of ultrasonic joining of textile materials. Int J Cloth Sci Tech 2000; 12: 331-350.

25. Hustedt M, Stein J, Herzog D, et al. Laser-based joining of technical textiles for airbag production. In: Third world automotive congress plastics-in-motion, Prague, Czech Republic, 14-16 May 2008, pp.1-11.

26. Wêglowska A. Effect of vibration welding parameters on the quality of joints made of polyamide 66. Polymer 2014; 59: 239-245.

27. Renumadhavi C, Madhava-Kumar S, Ananth AG, et al. A new approach for evaluating SNR of ECG signals and its implementation. In: Proceedings of the 6th WSEAS international conference on simulation. modelling and optimization, World Scientific and Engineering Academy and Society (WSEAS) Stevens Point, WI, 2006, pp.202-205.

28. Kursun-Bahadir S, Koncar V, Kalaoglu F, et al. Assessing the signal quality of an ultrasonic sensor on different conductive yarns used as transmission lines. Fibres Text East Eur 2011; 19: 75-81.

29. Wonnacott TH and Wonnacott JR. Introductory statistics. New York: Wiley: University of Western Ontario, 1990.

30. Kursun-Bahadir S, Kalaoglu F and Jevšnik S. The use of hot air welding technologies for manufacturing e-textile transmission lines. Fibers Polym 2015; 16: 1384-1394.

31. Jevšnik S. Predicting mechanical properties of fused panel. Fibres Text East Eur 2000; 8: 54-56.

32. Alagirusamy $\mathrm{R}$, Eichhoff $\mathrm{J}$, Gries $\mathrm{T}$, et al. J Text Inst 2013; 104: 270-277.

33. Rehnby W, Gustafsson M and Skrifvars M. Polymers for smart textile applications. In: proceedings of ambience'08, Borås, Sweden, 2008, pp.100-103.

34. Ward Silver H. Transmission lines. The ARRL handbook for radio communications, 87 th ed. Newington CT USA: Amer Radio Relay League, 2009. 